\title{
Epidemiology of chronic obstructive pulmonary disease: a descriptive study in the mid-western region of Nepal
}

This article was published in the following Dove Press journal:

International Journal of COPD

4 April 2012

Number of times this article has been viewed

\author{
Ramjee Bhandari' \\ Rajan Sharma ${ }^{2}$ \\ 'Health Research and Social \\ Development Forum, ${ }^{2}$ Integrated \\ Rural Health Development Training \\ Center, Kathmandu, Nepal
}

\begin{abstract}
Background: The purpose of this study was to analyze the distribution of chronic obstructive pulmonary disease (COPD) in terms of time, place, and person among inpatients at the Mid Western Regional Hospital (MWRH) in Nepal.

Methods: A descriptive cross-sectional study was carried out by analyzing trends using secondary data for the fiscal years 2006-2009 in the inpatient department of the MWRH.

Results: The majority of patients admitted for treatment of COPD were women (60\%) and from higher ethnic groups (having a comparative advantage in terms of social and economic status), with a greater prevalence among those aged $60-69$ years (37\% of overall cases). The incidence of COPD increased in consecutive years, with the highest load during the winter months. The cases were most concentrated in places with easiest access to the hospital.

Conclusion: COPD was found in higher proportions among women, those aged 60-69 years, and upper caste groups, during the cold months, and among residents of areas near the hospital in the mid-western region of Nepal. It is recommended that further detailed research and health education regarding COPD be carried out to reduce its burden and associated losses.
\end{abstract}

Keywords: chronic obstructive pulmonary disease, Mid Western Regional Hospital, Surkhet, trend

\section{Introduction}

Chronic obstructive pulmonary disease (COPD) is the slow progressive destruction of airways characterized by gradual loss of lung function, which is a combination of chronic bronchitis and emphysema. ${ }^{1}$ Globally, $10 \%-20 \%$ of the population older than 40 years (an estimated 80 million) are COPD sufferers, resulting in more than 3 million deaths each year. ${ }^{1,2}$ COPD is projected to be the third leading cause of death by the year 2020. ${ }^{3,4}$ According to surveys by the Asian Pacific Society of Respiratory Diseases, $6.2 \%$ of the global COPD burden is born by 11 Asian countries. ${ }^{5}$ In Nepal, COPD accounts for $43 \%$ of the noncommunicable disease burden, and $2.56 \%$ of hospitalizations. ${ }^{6,7}$

Though tobacco smoking is established as the primary cause of COPD, indoor air pollution from biomass and/or traditional fuels is estimated to be associated with 0.4 million deaths from acute symptoms of COPD. ${ }^{5}$ Studies have shown that smokers in Nepal have a 70\% greater chance of developing COPD. ${ }^{6}$ In Nepal, more than $85 \%$ of households (98\% in rural areas) still rely on biomass fuel. ${ }^{8}$ Nepalese women are at higher risk of developing COPD through exposure to indoor air pollution; additionally, about $15 \%$ of women also smoke tobacco. ${ }^{9,10}$

Nepal has a diverse caste system that plays a significant role in determining the social and economic status of its people. The Health Management Information System 
has classified Nepalese ethnicities into six different groups, from "upper caste" to the Dalits (Figure 1). Higher ethnic groups, comprising $30.7 \%$ of the total population, are those having a comparative advantage in terms of socioeconomic status and higher utilization rates of services provided by the state. ${ }^{11}$ Dalits, comprising almost $20 \%$ of the total population, are considered the most hard to reach group in the context of delivery of health care services. ${ }^{12}$

The mid-western development region of Nepal consists of a privately run medical college and 17 public hospitals, of which the Mid Western Regional Hospital (MWRH) is the referral center within the public hospital/health facility network in the region. ${ }^{13}$ Assessment of visits made to the MWRH helps identify the disease patterns in the whole region. Present figures show that COPD morbidity and mortality in developing countries is continuing to increase. Therefore, it is important to understand the person, place, and time distribution which can inform and support programs that help decrease the burden of COPD.

\section{Materials and methods}

A descriptive, cross-sectional study was designed to describe the distribution of COPD cases at the MWRH. This was done by utilizing secondary data recorded in three different fiscal years for 2006-2009 from all inpatients admitted with COPD to the MWRH. Sources of information were the Health Management Information System register and patient records at MWRH.

Patients diagnosed with COPD according to the International Classification of Diseases and treated in the inpatient department comprised the study units. Manual segregation of the hospital data was performed to identify COPD cases admitted to the inpatient department. Details of 313 COPD patients registered in the three study years (70, 102, and 141, respectively) were analyzed and described on the basis of their distribution in terms of person, place, and time. Analysis involved editing, tabulation, comparison, and interpretation, utilizing Microsoft Excel. The variables studied were time (year and month), place (village development committees and municipality), and person (age, gender, and ethnicity). Ethnic disparities in health outcomes have been found to be crucial in the Nepalese context because upper caste groups have better health indicators compared with others. Ethnic classification in this study was based on the Health Management Information System, Department of Health Services, Ministry of Health and Population.

\section{Results}

The analysis of COPD patients showed a greater number $(60 \%)$ of females with this diagnosis (see Figure 2). The majority of cases were found among those aged 50-79 years, with the highest prevalence of all COPD patients among those aged 60-69 years (37\%) in the three fiscal years. The lowest prevalence was found in those under 40 years of age, with this age group accounting for less than $4 \%$ of all cases (see Figure 3). Among the ethnic groups, the highest proportion of COPD patients were of the upper caste, followed by the Dalit (a socioeconomically disadvantaged group in Nepal) and Janajati (an indigenous disadvantaged group). Factors such as service utilization, awareness level, and income may be factors associated with the majority of hospital admissions with COPD amongst the upper castes (see Figure 4).

The highest numbers of COPD patients were admitted during the month of February, followed by April, May, and January. More than half of the cases were seen during the last 5 months of each year. More cases were recorded during the winter months in all three study years. The percentage share of COPD among total inpatient cases showed an increasing trend (see Figure 5). Cases increased by more than $1 \%$ in 2008-2009 compared with 2006-2007 (see Table 1).

Because the study was conducted in the MWRH, most of the cases were from the Birendranagar municipality (almost $47 \%$ of all cases in the three fiscal years) and its

- Dalits: hills of Kami, Damai, Sharki, Gaine, Badi

- Disadvantaged Janajati: hills of Magar, Tamang, Rai, Limbu, Sherpa, Bhote, Walung, Sunuwar, Kumal, Jirel, Danuwar, Thami, Raji

- Disadvantaged non Dalit Terai caste groups: Yadav, Teli

- Religious minorities: Muslims, Chureto

- Relatively advantaged Janajatis: Newar, Thakali, Gurung

Upper caste groups: Brahmin, Chhetri, Thakuri, Sanyashi, Raajput, Kayastha, Baniya, Marwadi, Jaire, Nurang, Bengali

Figure I Ethnic codes as defined by the Health Management Information System. 


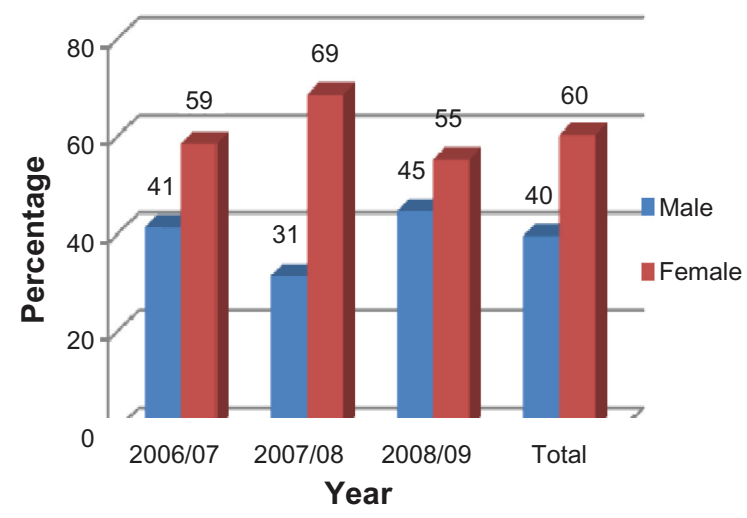

Figure 2 Gender distribution of patients with chronic obstructive pulmonary disease.

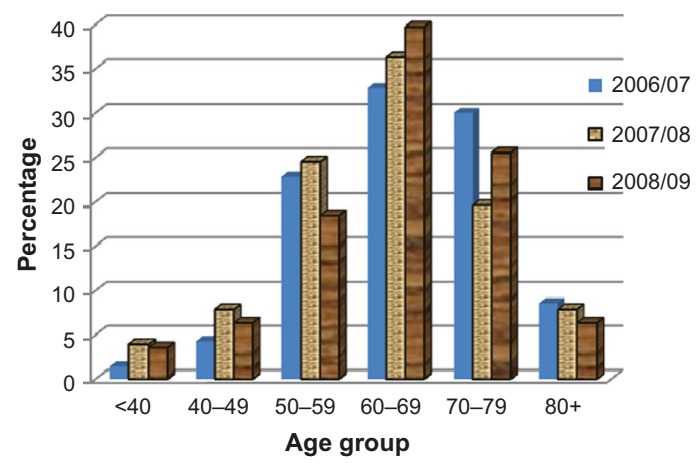

Figure 3 Age distribution of patients with chronic obstructive pulmonary disease.

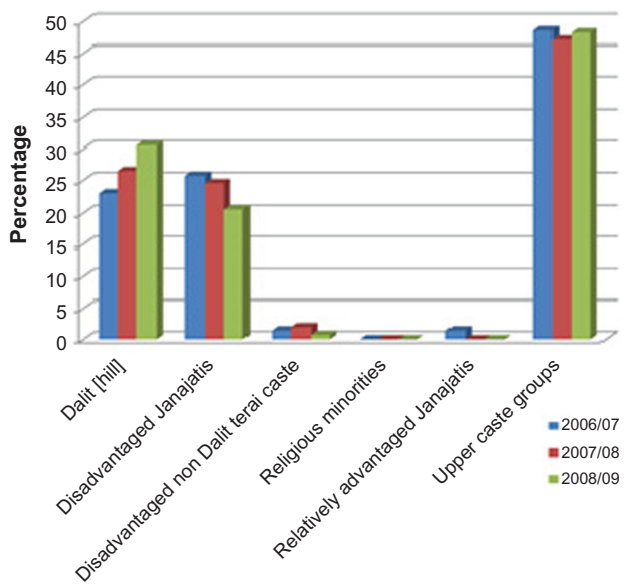

Figure 4 Ethnic distribution of patients with chronic obstructive pulmonary disease.

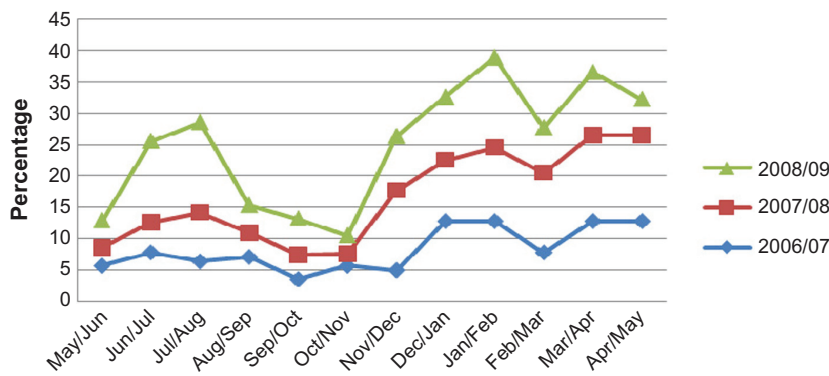

Figure $\mathbf{5}$ Monthly distribution of patients with chronic obstructive pulmonary disease.
Table I Share of COPD among total inpatient department cases

\begin{tabular}{lllll}
\hline SN & Year & $\begin{array}{l}\text { Total IPD } \\
\text { cases }\end{array}$ & $\begin{array}{l}\text { Total COPD } \\
\text { cases }\end{array}$ & $\begin{array}{l}\text { \% share of COPD } \\
\text { among IPD }\end{array}$ \\
\hline 1 & $2006 / 07$ & 3385 & 70 & 2.07 \\
2 & $2007 / 08$ & 3622 & 102 & 2.82 \\
3 & $2008 / 09$ & 4317 & 141 & 3.27 \\
& Total & 11324 & 313 & 2.76 \\
\hline
\end{tabular}

Abbreviations: COPD, chronic obstructive pulmonary disease; IPD, inpatient department.

surrounding village development committees, including Latikoili, Uttarganga, and Jarbuta (see Table 2). This does not suggest a high prevalence in those areas, but the catchment area of the hospital and geographical accessibility may be a key reason.

\section{Discussion}

This study was conducted to analyze COPD trends in terms of time, place, and person, and to provide background data for planning, organizing, and evaluation of COPD in the Surkhet district, as well as the mid-western region, by analysis of secondary data obtained from the inpatient department of the MWRH. Though the majority of the patients admitted to the hospital were from the Birendranagar municipality, a considerable number were from other parts of Surkhet and the whole region.

Our study identified a significant proportion of the COPD burden as being borne by women (six female sufferers for every ten cases of COPD). This figure suggests that the extensive use of biomass fuel by women living in rural communities puts women at increased risk of exposure to indoor air pollution for comparatively long periods of time. The same finding of biomass fuel being associated with COPD has been reported by several studies conducted in Nepal and other developing countries, with women being disproportionately affected. ${ }^{14-16}$

COPD was found to be less prevalent among people under 40 years of age. The proportion of COPD sufferers showed an incremental increase in prevalence with increasing age, reaching a peak in those aged 60-69 years, followed by a decrease in those aged older than 70 years. The declining rate of COPD after the age of 69 years may reflect the average life expectancy in Nepal, which is 67.1 years. ${ }^{17}$ The findings of the age-specific distribution of COPD are consistent with international findings. ${ }^{1}$ Several papers suggest that patients aged 40-65 years comprise more than half of the total number of COPD patients worldwide. ${ }^{18}$

Though the proportion of upper caste ethnic groups with COPD was found to be highest, followed by Dalit and 
Table 2 Distribution of patients with chronic obstructive pulmonary disease according to place

\begin{tabular}{|c|c|c|c|c|c|c|}
\hline SN & $\begin{array}{l}\text { Village development } \\
\text { committee/municipality }\end{array}$ & $2006 / 07$ & $2007 / 08$ & $2008 / 09$ & Total & Percentage \\
\hline I & Birendranagar & 34 & 51 & 62 & 147 & 46.96 \\
\hline 2 & Latikoili & 6 & 9 & 26 & $4 I$ & 13.10 \\
\hline 3 & Uttarganga & 12 & 12 & 15 & 39 & 12.46 \\
\hline 4 & Jarbuta & 3 & 5 & 6 & 14 & 4.47 \\
\hline 5 & Lekhparajul & I & 4 & 8 & 13 & 4.15 \\
\hline 6 & Salkot & 0 & 4 & 4 & 8 & 2.56 \\
\hline 7 & Pokharakanda & 0 & I & 4 & 5 & 1.60 \\
\hline 8 & Dasarathpur & 0 & 3 & 2 & 5 & 1.60 \\
\hline 9 & Sahare & I & 2 & I & 4 & 1.28 \\
\hline \multirow[t]{2}{*}{10} & Others & 13 & II & 13 & 37 & 11.82 \\
\hline & Total & 70 & 102 & $|4|$ & 313 & 100.00 \\
\hline
\end{tabular}

the disadvantaged Janajati, factors such as greater population density, higher service utilization, awareness level, and income among the upper ethnic groups may be associated factors. The data follow trends suggested in nationwide research conducted by the Nepal Health Research Council. ${ }^{6}$

Symptomatic COPD or its acute exacerbation was more common during the winter months, starting from November, after which a sharp rise in case load was observed in the later months of the year. The winter peaks are higher in some years than in others, but the timing of the peaks is usually the same. Our findings are similar to those of a COPD study conducted in India. ${ }^{19}$

Though our study identified cases as being concentrated in close proximity to the hospital, it can further be stated that service utilization and accessibility among local populations surrounding the Birendranagar municipality and the hospital catchment area may be a key factor, and not an increased prevalence of COPD in the general population of the Birendranagar municipality.

\section{Conclusion}

This descriptive study carried out in the MWRH of Nepal shows that the morbidity associated with COPD is higher among females, and that the disease seems to increase with age over 40 years, reaching a peak in those aged 60-69 years. COPD was more of a problem during the winter season, and the level of service utilization in symptomatic COPD cases was higher in and around the municipality where health care services were easily accessible. Though COPD has been widely accepted as a debilitating condition that drastically affects the lives of those diagnosed with the disease, timely diagnosis and management can slow progression of the illness. This study highlights distribution of the disease in terms of person, place, and time, and also underscores the need for more detailed research to identify factors underlying the condition. Effective interventions aimed at reducing risk factors and readiness to address the problems associated with the disease during the winter months would minimize the losses associated with COPD.

\section{Acknowledgments}

The authors would like to acknowledge all the faculties of the Department of Community Medicine and Family Health, Institute of Medicine, for their guidance and support throughout the fieldwork. We are grateful to Michael G Bare, MPH candidate at New York Medical College, for his constructive suggestions regarding this work. Special thanks goes to Ramesh Adhikari (former district public health officer, Surkhet) and Binod Basnet (medical recorder, MWRH) for providing the necessary data as well as support during the study period. Similarly, we appreciated the efforts of Madhav Bhusal, Pratima Parajuli, and Ramesh Bastola in data compilation.

\section{Disclosure}

The authors report no conflicts of interest in this work.

\section{References}

1. Longmore JM. Oxford Handbook of Clinical Medicine. 8th ed. Oxford, UK: Oxford University Press; 2010.

2. World Health Organization. Chronic Obstructive Pulmonary Disease. Geneva, Switzerland: Office of Health Communications and Public Relations; 2007.

3. Murray CJL, Lopez AD. The Global Burden of Disease: A Comprehensive Assessment of Mortality and Disability from Diseases, Injuries, and Risk Factors in 1990 and Projected to 2020. Geneva, Switzerland: World Health Organization; 1996.

4. Global Initiative for Chronic Obstructive Lung Disease. Global Strategy for the Diagnosis, Management and Prevention of Chronic Obstructive Lung Disease. Edgewater, NJ: MCR Vision Inc; 2006.

5. COPD-International.com. COPD statistical information. Available from: http://www.copd-international.com/library/statistics.htm. Accessed October 24, 2011.

6. Nepal Health Research Council. Prevalence of Non Communicable Disease in Nepal: Hospital Based Study. Kathmandu, Nepal: Nepal Health Research Council; 2010. 
7. Department of Health Services. Annual report. In: Ministry of Health and Population. Kathmandu, Nepal: Department of Health Services; 2009/10.

8. Winrock International Nepal. Household energy, indoor air pollution and health impacts: status report for Nepal 2004. Available from: http://pdf. usaid.gov/pdf_docs/PNADO853.pdf. Accessed February 23, 2012.

9. Pandey MR. Health effects of indoor air pollution. Available from: http://www.arecop.org/publications/glow/zip/glow200302vol29.pdf. Accessed February 23, 2012.

10. Ministry of Health and Population. Brief profile on tobacco control in Nepal. In: Government of Nepal. Kathmandu, Nepal: Ministry of Health and Population; 2010.

11. Central Bureau of Statistics. Population distribution by caste/ethnic groups and sex for Nepal. In: National Planning Commission. Kathmandu, Nepal: Central Bureau of Statistics; 2001.

12. The missing piece of the puzzle: Caste discrimination and the conflict in Nepal, 2005. Available from: http://www.chrgj.org/docs/Missing\%20 Piece\%20of\%20the\%20Puzzle.pdf. Accessed February 23, 2012.
13. Mid-Western Regional Health Directorate. Integrated regional health sector strategy and periodic plan. Available from: http://mwrhd.gov. np/. Accessed February 23, 2012.

14. Pandey MR. Prevalence of chronic bronchitis in a rural community of the Hill region of Nepal. Thorax. 1984;39:331-336.

15. Behera D, Jindal SK. Respiratory symptoms in Indian women using domestic cooking fuels. Chest. 1991;100:385-388.

16. Dennis RJ, Maldonado D, Norman S, et al. Wood smoke exposure and risk for obstructive airways disease among women. Chest. 1996; 109 Suppl 3:55S-56S.

17. World Bank. World Development Indicators. Washington, DC: World Bank; 2011.

18. International COPD coalition. COPD Uncovered, 2010. Available from: http://www.internationalcopd.org/documents/COPD_Uncovered_ Report.pdf. Accessed November 1, 2011.

19. Chandra D, Guleria R. Effects of seasonal variation on hospitalisations for acute exacerbations of chronic obstructive pulmonary disease. Indian $J$ Chest Dis Allied Sci. 2009;51:139-143.

\section{Publish your work in this journal}

The International Journal of COPD is an international, peer-reviewed journal of therapeutics and pharmacology focusing on concise rapid reporting of clinical studies and reviews in COPD. Special focus is given to the pathophysiological processes underlying the disease, intervention programs, patient focused education, and self management protocols.

\section{Dovepress}

This journal is indexed on PubMed Central, MedLine and CAS. The manuscript management system is completely online and includes a very quick and fair peer-review system, which is all easy to use. Visit http://www.dovepress.com/testimonials.php to read real quotes from published authors. 